\title{
Organic foreign body causing lung collapse and bronchopleural fistula with empyema
}

\author{
Pierre Goussard, ${ }^{1}$ Robert Gie, ${ }^{1}$ Savvas Andronikou, ${ }^{2}$ Julie Lyn Morrison ${ }^{1}$
}

${ }^{1}$ Department of Paediatrics and Child Health, Stellenbosch University, Cape Town, Western Cape, South Africa ${ }^{2}$ Department of Radiology, University of the

Witwatersrand, Johannesburg, South Africa

\section{Correspondence to}

Dr Pierre Goussard, pgouss@sun.ac.za

Accepted 12 March 2014

\section{DESCRIPTION}

A 10-month-old infant presented with cough and fever. Treatment with oral antibiotics was initiated but the infant was admitted to hospital 7 days later, severely ill with a high-swinging fever. On clinical examination of the chest there were reduced breath sounds in the area of the right lower lobe.

The initial chest X-ray (figure 1A) taken on admission to hospital demonstrated right-sided pleural effusion as well as parenchymal opacities of the right lower lung region. Although the chest $\mathrm{X}$-ray was rotated to the right there was a suggestion that the mediastinum was displaced to the left.

In a contrasted $\mathrm{CT}$ scan of the chest (figure $2 \mathrm{~A}, \mathrm{~B}$ ) right lower lobe air-space volume loss with breakdown and cavitation was noted. The parenchymal pathology was complicated by a large pyopneumothorax with loculated pockets of pleural air (with an anterior air-fluid level) indicative of a pleuroparenchymal fistula being present.

On careful questioning the father remembered that the child had 3 months previous to admission choked after putting an unidentified object in his mouth while playing in the garden. Since the choking episode the infant had developed a persistent cough.

Prior to performing a right-sided lateral thoracotomy to drain the empyema, a fiberoptic bronchoscopy was performed under general anaesthesia. A $2.8 \mathrm{~mm}$ video scope with a $1.2 \mathrm{~mm}$ working channel was inserted into the airway via a laryngeal mask airway. After lavaging out a large amount of purulent

secretions from the right lobe it became apparent that the right lower lobe bronchus was largely destroyed and unusual lung parenchyma could be visualised through the bronchoscope. In one of the subsegmental bronchi a foreign body was visible. The foreign body was removed via the fiberoptic bronchoscope with the aid of biopsy forceps which were introduced via the $1.2 \mathrm{~mm}$ working channel. The foreign body was identified to be a $2 \mathrm{~cm}$ long twig of a tree. Following the bronchoscopy, the right-sided thoracotomy was performed. On examination of the underlying lung, there was a $0.5 \mathrm{~mm}$ tract created by the twig penetrating the lung parenchyma into the pleural cavity, demonstrating the cause of the loculated pyopneumothorax. Post-thoracotomy there was immediate improvement in the infant's clinical and radiological picture (figure 1B). The improvement was maintained and the infant remains asymptomatic.

This case illustrates that foreign body aspiration can occur even in young infants, that foreign body aspiration should be considered in complicated lung infections, and the value of taking a careful history even if the aspiration occurred months previously.
A

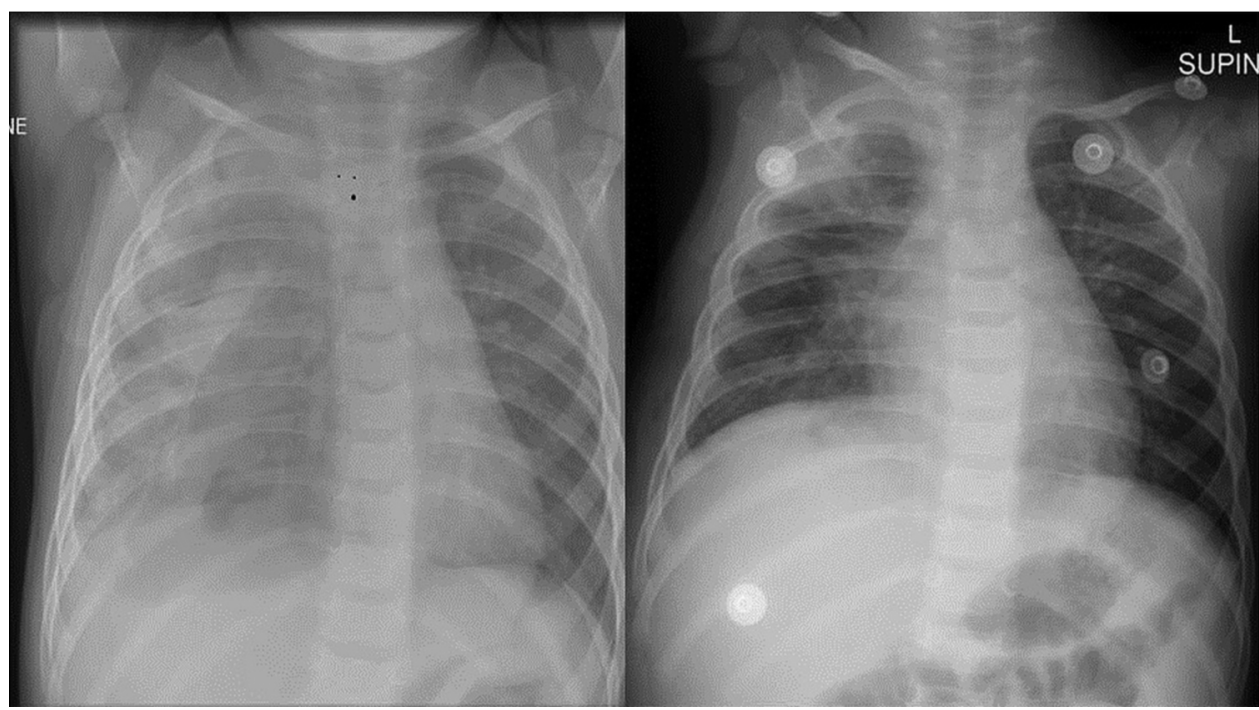

Figure 1 (A) Initial chest X-ray examination. There are ill-defined pleural-based densities involving the right hemithorax as well as underlying parenchymal air-space disease with air bronchograms and loss of the diaphragmatic and right cardiac margins. There is mediastinal shift even in the presence of rotation to the right, which disguises this to a degree. There are no pleural air-pockets or pneumothorax on this radiograph. (B) Postoperative chest X-ray demonstrates significant improvement with small residual pleural effusions tracking laterally and re-expansion of the lower lobe. There is some residual air-space disease involving the upper lobe. The mediastinum has regained its normal position. 
A B

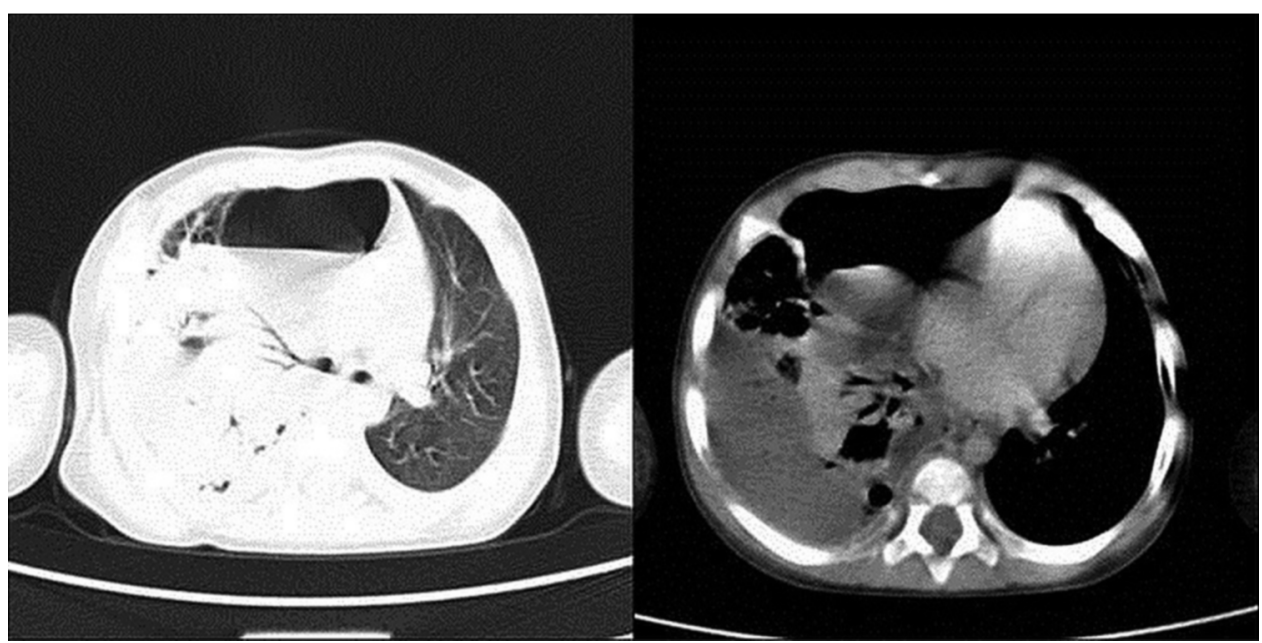

Figure 2 ( $\mathrm{A}$ and $\mathrm{B})$ Axial postcontrast $\mathrm{CT}$ of the chest demonstrating features of lung infection with pleural disease suggesting pleuroparenchymal fistula. (A) The postcontrast CT of the lung and pleura on mediastinal window, below the level of the carina, demonstrates the collapsed and consolidated lower lobe with cavitation of a segment posteriorly showing communication with a bronchus as well as pockets of pleural air posteriorly. In addition there is a loculated pleural collection of intermediate CT density and a large pocket of pleural air in the non-dependent portion of the chest. The mediastinum is displaced to the left. (B) Axial CT slice just below the level of the carina on lung windows confirms the air-space process in the right lower lobe, demonstrates small pockets of pleural air and also a large pleural air-fluid level anteriorly.

Late-diagnosed bronchial foreign bodies can lead to irreversible changes in the bronchi and the lungs. Delayed diagnosis of foreign body aspiration is not uncommon in the developing world, leading to lobar collapse and bronchiectasis. ${ }^{1}$ In contrast to this only $51 \%$ of cases of foreign body aspiration present with

\section{Learning points}

- The development of a bronchopleural fistula with empyema is a rare presentation of foreign body aspiration in infants and children.

- The most valuable clinical clue to foreign body aspiration is decreased breath sounds over a lung or lobe.

- It is important to ask about foreign body aspiration while taking the patient's history. an abnormal chest X-ray often leading to an incorrect diagnosis. ${ }^{2}$ The development of a bronchopleural fistula with empyema is a rare presentation of foreign body aspiration in infants and children but emphasises the point that foreign body aspiration must be considered in all cases of unusual lung disease.

Contributors PG, RG and JLM were responsible for the clinical management and postoperative management of the patient. SA was responsible for the radiological evaluation of the patient.

\section{Competing interests None.}

\section{Patient consent Obtained.}

Provenance and peer review Not commissioned; externally peer reviewed.

\section{REFERENCES}

1 Duan $\mathrm{L}$, Chen $\mathrm{X}$, Wang $\mathrm{H}$, et al. Surgical treatment of late-diagnosed bronchial foreign body aspiration: a report of 23 cases. Clin Respir J 2013. doi:10.1111/crj. 12040

2 Oncel M, Sunam GS, Ceran S. Tracheobronchial aspiration of foreign bodies and rigid bronchoscopy in children. Pediatr Int 2012;54:532-5.

Copyright 2014 BMJ Publishing Group. All rights reserved. For permission to reuse any of this content visit

http://group.bmj.com/group/rights-licensing/permissions.

BMJ Case Report Fellows may re-use this article for personal use and teaching without any further permission.

Become a Fellow of BMJ Case Reports today and you can:

- Submit as many cases as you like

- Enjoy fast sympathetic peer review and rapid publication of accepted articles

- Access all the published articles

- Re-use any of the published material for personal use and teaching without further permission

For information on Institutional Fellowships contact consortiasales@bmjgroup.com

Visit casereports.bmj.com for more articles like this and to become a Fellow 